\title{
História e verdade para além da virada linguística: a contribuição de Frank Ankersmit
}

History and truth beyond the linguistic turn: Frank Ankersmit's contribution

ANKERSMIT, Franklin Rudolf. A escrita da História: a natureza da representação histórica. Londrina: Eduel, 2012, 338 p.

\section{Gilvan Ventura da Silva}

gil-ventura@uol.com.br

Professor associado

Universidade Federal do Espírito Santo

Av. Fernando Ferrari, 514

29075-910 - Vitória - ES

Brasil

Palavras-chave

História; Verdade; Historiografia.

Keywords

History; Truth; Historiography. 
Há alguns anos temos acompanhado, nos meios acadêmicos brasileiros, um desenvolvimento sem precedentes de subáreas do conhecimento histórico que durante décadas ocuparam uma posição secundária diante da história pátria, como se o fazer histórico, em termos profissionais, fosse apanágio dos pesquisadores dedicados ao estudo da História do Brasil, tanto em termos próprios quanto na interface com a História Moderna, a História Contemporânea e a História da América, procedimento que, no limite, convertia essas "outras histórias" em ramos subsidiários da história nacional. Felizmente, esse quadro parece estar se revertendo pouco a pouco, não no sentido de diminuir ou enfraquecer o interesse pela nossa experiência colonial, imperial ou republicana, hipótese no mínimo descabida, mas no de exprimir a pujança, a diversidade e a criatividade de um saber cuja antiguidade remonta, pelo menos, aos gregos da época clássica. Num contexto como esse, é de se saudar o florescimento de especialidades que, embora consolidadas de longa data em universidades e institutos de pesquisa estrangeiros, ainda carecem, no País, de maior investimento, movimento sem dúvida alavancado pela afirmação definitiva do Brasil no cenário internacional, o que tem levado os pesquisadores a uma interlocução cada vez mais estreita com os seus pares distribuídos por todo o planeta. Os efeitos desse desejo em explorar outras dimensões do passado têm-se feito sentir, por exemplo, na História Antiga, na História Medieval, na História da África e, no que nos interessa aqui, na Teoria e Metodologia da História, domínio fronteiriço entre a História e a Filosofia que tem adquirido entre nós uma admirável densidade intelectual, revelando aos historiadores brasileiros problemáticas inerentes ao seu mestiere até então ignoradas ou parcamente conhecidas, o que caminha pari passu com a divulgação do trabalho de autores que, não obstante a solidez da sua formação intelectual, a originalidade e profundidade de seu pensamento, são ainda pouco lidos e quiçá estudados.

Esse é o caso, por exemplo, do filósofo e historiador holandês Frank Rudolf Ankersmit. Nascido em 1945, Ankersmit passou a ocupar, em 1992, a cadeira de História Intelectual e Teoria da História e Historiografia da Universidade de Groningen, tendo se notabilizado pelas reflexões acerca do método histórico, com destaque para os conceitos de narrativa e de representação. A trajetória de Ankersmit como historiador e teórico da História inicia-se com a publicação da tese Narrative logic: a semantic analisys of the historian's language, em 1983, na qual o autor discute as relações entre a interpretação histórica e o passado com base no que denomina "substância narrativa", defendendo que o principal critério para se aferir a plausibilidade da narrativa histórica seria o seu escopo explicativo e não a "verdade" nela contida. A despeito de sua relevância, a obra de Ankersmit se encontra ainda, majoritariamente, em língua estrangeira, sendo poucos os seus textos acessíveis ao grande público em língua portuguesa, dentre os quais inclui-se o artigo "Historiografia e pós-modernismo", publicado pela revista Topoi no número 2, referente a janeiro-junho de $2001 .{ }^{1}$ Suprir em 
parte essa lacuna é um mérito importante, mas não o único, do livro $A$ escrita da História: a natureza da representação histórica, uma coletânea de ensaios publicados em inglês entre 1994 e 2012 de cuja tradução e organização se incumbiram Alfredo dos Santos Oliva, Gabriel Giannattasio, Gisele Iecker de Almeida, Jonathan Menezes e Maria Siqueira Santos, pesquisadores vinculados à Universidade Estadual de Londrina, responsáveis ainda por uma entrevista inédita com o autor. O próprio Ankersmit, por sua vez, se encarregou de escrever um prefácio à edição brasileira no qual sumariza as principais fases pelas quais passaram a Filosofia e Teoria da História desde a época de Hegel, Marx e Toynbee, no século XIX, até Hayden White, que em 1973, com a publicação de Meta-História, redefiniu o debate acerca da natureza do conhecimento histórico ao enfatizar os condicionantes textuais e, portanto, linguísticos, do trabalho do historiador, demonstrando o quanto este é dependente das estruturas narrativas, uma vez que, ao fim e ao cabo, seu ofício desemboca na produção de um texto com enredo e personagens, afirmação que à época gerou autêntico furor entre os defensores de uma História comprometida com a veracidade dos fatos, que se julgaram subitamente ameaçados pelo relativismo e pelo irracionalismo.

Ankersmit, ao longo dos oito capítulos que integram a coletânea, não se furta a reconhecer, em mais de uma oportunidade, a dívida intelectual que mantém com Hayden White, pois, assim como este, acredita que os relatos históricos são difusores, não de explicações "verdadeiras" acerca dos acontecimentos pretéritos, mas de representações, sob a forma de imagens, metáforas e analogias, desse território opaco, nebuloso e, no limite, inapreensível que chamamos de passado. Todavia, num confronto direto com os seus críticos, que se apressam em atribuir-Ihe os rótulos de narrativista e idealista, querendo com isso enfatizar uma filiação inconteste com Hayden White, Ankersmit faz questão de recuperar, nas entrelinhas de suas reflexões, o compromisso da História com a "verdade" ou a "verossimilhança" dos processos analisados. Agindo assim, busca escapar do apego excessivo de White aos aspectos formais do texto histórico a fim de alcançar o teor epistemológico da relação entre a escrita da história e o passado, uma relação que não se esgota na discussão sobre se as narrativas históricas são apenas isso: narrativas dependentes dos códigos da língua, que as conformariam e ao mesmo tempo as reduziriam a artefatos textuais, isentos de qualquer ancoragem no real, seja lá o que isso signifique, mas que pretende superar o relativismo embutido na assim denominada Virada Linguística, de modo a nos permitir discriminar entre explicações que façam melhor justiça ao passado do que outras.

Um dos eixos do pensamento de Ankersmit é o pressuposto segundo o qual toda narrativa histórica deve ser compreendida como uma proposta de interpretação/explicação acerca das características e condicionantes de um dado processo. Tais propostas permitem organizar, num relato inteligível, aspectos do passado que os historiadores julgam relevantes, devendo exprimir, desde o início unidade e coesão, caso contrário seriam facilmente refutadas no torvelinho do debate incessante que caracteriza a historiografia. A essa altura, uma questão que logo se impõe é a seguinte: seriam tais "unidade" e "coesão" 
propriedades do passado mesmo, ou antes diriam respeito apenas ao discurso (literário) produzido pelo historiador, o que nos remeteria à indagação sobre a transparência/opacidade entre linguagem e realidade? Seriam as palavras capazes de descrever de modo eficiente os seres e as coisas observáveis no mundo? Haveria, portanto, a possibilidade de um enunciado verbal que contivesse, nele mesmo, uma parcela, por mínima que fosse, da concretude do mundo e, como tal, pudesse se constituir como um enunciado sobre algo "verdadeiro", posto que factível, e não como uma mera convenção linguístico-cultural? Essas são questões cruciais enfrentadas por Ankersmit na tentativa, por um lado, de resguardar os ganhos intelectuais da Virada Linguística para a História, mas, por outro lado, de superar o seu calcanhar de Aquiles, isto é, o relativismo extremo que parece dominar as reflexões de autores como Hayden White e Dominick LaCapra, e que os torna figuras indesejáveis entre os historiadores. Ankersmit busca solucionar o dilema propondo que a especificidade do texto histórico - e por que não o dizer, seu principal atrativo? - resulta da associação que nele se opera entre o nível da "fala" (verdade empírica) e o da "fala sobre a fala" (verdade analítica). O texto histórico contém o nível da "fala" pelo fato de descrever o passado em termos pontuais, passíveis de comprovação direta, como quando dizemos que a Lei Áurea foi assinada no ano de 1888 por uma personagem intitulada Princesa Isabel, mas contém ainda o nível da "fala sobre a fala" ao sugerir conexões entre os acontecimentos por meio de conceitos como "Renascimento" e "Revolução", que pretendem, com o recurso da língua, organizar de modo inteligível uma parcela do passado. A questão é saber se os conteúdos suportados pelos continentes "Renascimento" ou "Revolução" se aproximam mais ou menos da realidade vivida, se as ferramentas conceituais empregadas pelo historiador explicam de modo mais ou menos útil o passado. Para Ankersmit, a escrita da história não seria algo como uma arena de vale-tudo na qual os participantes teriam licença para desferir golpes a esmo, mas um saber que comporta regras capazes de conferir maior ou menor credibilidade às análises, uma importante salvaguarda contra as modalidades mais radicais de relativismo. De acordo com o autor, o avanço do conhecimento, em geral, depende não tanto do acúmulo de observações cuja verdade é sobejamente conhecida por todos, não havendo assim propósito em se realizar um inventário exaustivo de todas as formigas do planeta para concluir que esses insetos possuem antenas, mas da construção de sistemas teóricos que iluminem "verdades" capazes de acrescentar novas informações àquilo que já se sabia. Por essa razão, Ankersmit acredita ser possível formular relatos "verdadeiros" sobre o passado a partir não apenas da "fala" (do fato empírico em si), mas também da "fala sobre a fala", dos conceitos forjados à luz da linguagem, na medida em que estes venham a realçar conexões até então insuspeitas entre os fatos, permitindo-nos aprofundar a compreensão sobre o mundo.

Para a escrita da história nos termos sugeridos por Ankersmit, o conceito de representação adquire singular importância, uma vez que toda e qualquer representação, seja ela textual, gestual ou iconográfica, não exprime a totalidade do que é representado ou, dito de outro modo, não é capaz de revelar a essência 
ou verdade de algo, mas apenas por em relevo aspectos do objeto consoante a perspectiva do observador. Tal propriedade representativa é constituinte do trabalho do historiador que, ao se debruçar sobre o passado, não se reporta amiúde a objetos que possuem uma concretude - ou apenas o faz à guisa de introdução -, mas a processos que comportam alto nível de abstração e que não descrevem o real, o concreto, o visível, mas o nexo possível entre parcelas da realidade, como comprovam as referências, nos livros de história, a coisas que não possuem, digamos assim, uma face, a exemplo das revoluções, da industrialização ou do desenvolvimento econômico. Desse modo, segundo Ankersmit (2012, p. 194), "uma representação (1) define um representado (2) em termos dos quais o mundo (3) é visto - e devemos evitar a confusão entre (2) e (3)". Ao contrário do que poderíamos supor à primeira vista, conclusões como essas não invalidam os esforços do historiador no sentido de produzir a melhor representação (leia-se explicação histórica) possível sobre aquilo que representa, uma vez que o seu ofício se encontra fundado numa "epistemologia particularizada". O historiador, quando se volta para o estudo do passado valendo-se do seu ferramental teórico está, em última análise, respondendo, embora no âmbito de um caso específico, à questão epistemológica fundamental sobre como linguagem e realidade podem interagir, o que não é uma tarefa de pequena monta. O parâmetro entre representações mais ou menos bem sucedidas reside, segundo o autor, na própria configuração da historiografia, campo marcado por um confronto incessante de pontos de vista no qual os historiadores põem à 186 prova, dia após dia, a racionalidade e a pertinência das interpretações sobre o passado que elaboram e dos conceitos (linguísticos) mobilizados para sustentálas, de maneira que uma interpretação será mais ou menos digna de crédito na proporção inversa do debate que ela suscitar. Cremos ser possível afirmar, a título de conclusão, que os argumentos de Ankersmit em A escrita da História contribuem para tornar os historiadores menos cautelosos em face da Virada Linguística, pois o autor, ao definir a explicação histórica como uma modalidade de representação do passado mediada pela linguagem, não nega a possibilidade de que haja representações mais ou menos plausíveis - alguns talvez preferissem dizer mais ou menos "verdadeiras" -, opondo-se assim a um relativismo radical que, ao insistir sobre o caráter ficcional das narrativas históricas, termina por introduzir o irracionalismo na "oficina" dos historiadores, algo que Ankersmit se nega a admitir. 